\title{
AS RELAÇÕES ENTRE OS SUBSISTEMAS SOCIAIS DO DIREITO E DA POLÍTICA: SUSTENTABILIDADE, INTERFERÊNCIA E CORRUPÇÃO SISTÊMICA ${ }^{1}$
}

\author{
RELATIONS BETWEEN THE SOCIAL SUBSYSTEMS OF LAW AND POLICY: \\ SUSTAINABILITY, INTERFERENCE AND SYSTEMIC CORRUPTION
}

\section{Magno Federici Gomes}

\begin{abstract}
Estágio Pós-doutoral em Direito Público e Educação pela Universidade Nova de Lisboa-Portugal (Bolsa CAPES/BEX 3642/07-0). Estágios Pós-doutorais em Direito Civil e Processual Civil, Doutor em Direito e Mestre em Direito Processual, pela Universidad de Deusto-Espanha (Bolsa da Cátedra UNESCO e do Gobierno Vasco-

Espanha). Mestre em Educação pela PUC Minas. Professor do Doutorado e Mestrado Acadêmico em Direito Ambiental e Desenvolvimento Sustentável na Escola Superior Dom Helder Câmara. Professor Adjunto da PUC Minas e Professor Titular licenciado da Faculdade de Direito Arnaldo Janssen. E-mail: federici@pucminas.br
\end{abstract}

\section{Leandro Queiroz Gonçalves}

Mestrando em Direito Ambiental pela Escola Superior Dom Hélder Câmara. Graduado em Direito pela Pontifícia Universidade Católica de Minas Gerais. Assessor Judiciário do Tribunal de Justiça do Estado de Minas Gerais.

E-mail: lqueirozgoncalves@gmail.com

Recebido em: 05/07/2019

Aprovado em: 09/12/2019

RESUMO: O presente estudo trata da análise dos subsistemas sociais do Direito e da Política, marcadas pela interferência mútua cujo acoplamento estrutural é a Constituição do Estado. O problema que se pretende resolver é a sobreposição de um subsistema sobre o outro e sua afetação na diferenciação funcional que pode implicar em corrupção sistêmica, utilizando como marco a teoria dos sistemas sociais de Luhmann. Objetiva-se analisar a sustentabilidade da interferência do Poder Judiciário nas políticas públicas, utilizando-se o método teórico documental, com técnica dedutiva. Concluiu-se que a interferência excessiva entre os subsistemas pode levar à sobreposição das funções de um subsistema sobre o outro, levando à corrupção sistêmica.

Palavras-Chave: Sistemas sociais autopoiéticos; Direito; Política; Interferência; Corrupção sistêmica.

Abstract: The present study deals with the analysis of the social subsystems of Law and Politics, marked by mutual interference whose structural coupling is the Constitution of the State. The problem that is intended to solve is the overlapping of one system over the other and its affectation in the functional differentiation that can imply in systemic corruption, using as reference the Luhmann social systems theory. The objective is to analyze the sustainability of the interference

${ }^{1}$ Trabalho financiado pelo Projeto FAPEMIG no 22869, resultante dos Grupos de Pesquisas (CNPQ): Regulação Ambiental da Atividade Econômica Sustentável (REGA), NEGESP, Metamorfose Jurídica e CEDIS (FCT-PT).

Revista de Direito Brasileira | Florianópolis, SC | v. 24 | n. 9 | p.120-136 | Set./Dez. 2019 
of the Judiciary in public policies, using the documentary theoretical method, with deductive technique. It was concluded that excessive interference between systems can lead to overlapping functions of one subsystem sore the other, leading to systemic corruption.

Keywords: Autopoietic social systems; Right; Politics; Interference; Systemic Corruption.

SUMÁRIO: Introdução. 1 O Direito como subsistema social. 2 Distinção funcional entre direito e política. 3 Judicialização das políticas públicas e corrupção sistêmica. Considerações finais. Referências.

\section{INTRODUÇÃO}

A compreensão do funcionamento dos sistemas sociais nos quais se inserem o subsistema político e o subsistema do direito é fundamental para entender as características e as limitações de cada subsistema e como estes se relacionam dentro do ambiente social, trazendo importante substrato para que se analise em que medida o Poder Judiciário pode interferir na implementação de políticas públicas.

A utilização do termo subsistema neste trabalho, para designar os sistemas sociais do direito e da política, decorre do fato de constituírem subsistemas integrantes de um sistema maior que é o sistema social, embora se utilize tanto a definição de sistema do direito e da política, quanto de subsistema.

O pensamento teórico do Direito, com bases filosóficas, por si só, não é capaz de responder as questões referentes às demandas da sociedade pela realização de políticas públicas e como este fenômeno acabou por conduzir o Poder Judiciário à condição de protagonista, sobretudo a partir da Constituição da República de 1988 (CR/88), o que demanda um estudo voltado para a sociologia jurídica.

A análise do Direito como subsistema social, partindo-se de uma teoria originada da sociologia jurídica, mostra-se necessária para compreender melhor o subsistema jurídico além da tradicional teoria geral do direito, cuja análise se limita às características funcionais do Direito em um aspecto fechado, voltado para seu surgimento e aplicação, sem a compreensão de sua interrelação com os demais subsistemas sociais como o Econômico e o Político.

Surge então a necessidade de se compreender o fenômeno social que resultou no ativismo judicial à luz da teoria dos sistemas sociais de Niklas Luhmann, de modo a esclarecer as atribuições dos subsistemas jurídico e político, a forma como se inter-relacionam e de que maneira a interferência do ambiente (sociedade) provoca alterações internas nestes subsistemas.

O problema da pesquisa consiste em avaliar a sustentabilidade da interferência do Poder Judiciário na realização de políticas públicas, cuja competência cumpre ao Poder Executivo.

O objetivo consiste em analisar, por meio da teoria dos sistemas sociais autopoiéticos e de sua evolução, como a sociologia jurídica lida com a interferência entre os subsistemas do Direito e da Política.

Para a consecução dos objetivos deste trabalho será adotada metodologia de pesquisa qualitativa, quanto ao problema, e exploratória, quanto ao método, para que a partir de uma análise da teoria dos sistemas sociais seja possível a compreensão das limitações do Poder Judiciário na realização de políticas públicas. Utilizar-se-á a forma hipotético-dedutiva e a técnica de pesquisa bibliográfica, que fornecerá o suporte teórico para a análise do problema e proposição da hipótese, assim como a pesquisa documental, por meio da análise dos dispositivos legais. O marco teórico será Luhmann (2016a; 2016b e 1985).

O trabalho será desenvolvido a partir da definição do Direito como subsistema social autopoiético, evidenciando suas características operacionais como a linguagem e a capacidade de lidar com as interferências externas advindas do ambiente/sociedade. 
Definida a noção do Direito como subsistema social autopoiético serão traçados os elementos distintivos em relação aos subsistemas do Direito e da Política ${ }^{2}$, com ênfase nos aspectos funcionais e nas características de cada um dos subsistemas para lidar com as demandas advindas da sociedade, evidenciando, em cada subsistema, as limitações de sua linguagem para processar informações do ambiente.

Demonstrada a diferenciação funcional entre os referidos subsistemas passa-se à análise das possibilidades de interferência mútua ${ }^{3}$ entre eles e das consequências advindas destas interferências, sobretudo em relação à atuação do Poder Judiciário na implementação de políticas públicas, cuja atribuição está reservada ao Poder Executivo pelo texto constitucional.

\section{DIREITO COMO SUBSISTEMA SOCIAL AUTOPOIÉTICO}

A teoria dos sistemas sociais (LUHMANN, 2016b, p. 27) tem como fundamento a teoria geral dos sistemas, que por sua vez sofreu influências da teoria do organismo, derivada da biologia e da neurociência, da teoria citológica e da teoria computacional, que possibilitaram o desenvolvimento de uma teoria cujo paradigma se traspôs de "interesses em designs e controles para interesses em autonomia e em sensibilidade ambiental, de planejamento para evolução, de estabilidade estrutural para estabilidade dinâmica (LUHMANN, 2016b, p. 27)"”.

A teoria dos sistemas sociais tem como mérito a análise da sociedade com foco na compreensão dos organismos sociais e não no indivíduo, mostrando-se fundamental para aqueles que buscam compreender como o subsistema do Direito se relaciona com os demais subsistemas sociais e com a sociedade/ambiente.

É por meio da função e da linguagem limitadora ao código binário "lícito/ilícito" ou "jurídico/antijurídico" que o Direito se distingue dos demais sistemas sociais, sofrendo interferências externas que promovem a complexidade do sistema sem que perca a sua função, pois a assimilação do meio ambiente ocorre dentro das limitações impostas pela funcionalidade do sistema. Conforme adverte Neves (1996, p. 96), "o sistema jurídico assimila seletivamente, de acordo com os seus próprios critérios, os fatores do meio ambiente, não sendo diretamente influenciado por esses fatores"4.

Rocha e Duarte (2012, p. 16) afirmam que "a metodologia de Niklas Luhmann parte do pressuposto de que é possível comparar em uma teoria da sociedade diversos sistemas voltados para uma determinada função", o que possibilita analisar "campos heterogêneos como a Ciência, o Direito, a Economia e a Política, colocando-se de manifesto estruturas que podem ser comparadas" (ROCHA; DUARTE, 2012, p. 16).

Segundo Luhmann (2016b, p. 21-23), a evolução da teoria dos sistemas passa pela mudança da compreensão do sistema como "totalidade composta de partes" e "aquilo que era concebido como diferença entre todo e parte é reformulado como Teoria da Diferenciação Sistêmica e assim incorporado no novo paradigma[, adotando-se a diferenciação sistêmica sob o aspecto da] repetição da diferença entre sistema e ambiente" (LUHMANN, 2016b, p. 21-23). A diferenciação entre os sistemas evolui, portanto, para a compreensão de como os sistemas operam de formas distintas com o ambiente e como estas interações com o ambiente são capazes de reconstruir o sistema.

\footnotetext{
${ }^{2}$ A ênfase dada ao Direito como sistema autopoiético tem como objetivo traçar as bases do estudo quanto à sua evolução mediante interferência externa. Salienta-se que a noção de política também será estabelecida no decorrer do texto.

${ }^{3}$ As teorias de Neves (2012, p. 199-207) sobre a interferência mútua entre os subsistemas serão citadas no decorrer do trabalho.

${ }^{4}$ Salienta-se que, neste capítulo, pretende-se dar uma noção geral dos sistemas sociais, sem adentrar no subsistema jurídico.
}

Revista de Direito Brasileira | Florianópolis, SC | v. 24 | n. 9 | p.120-136 | Set./Dez. 2019 
Os sistemas sociais se diferenciam, portanto, pelo modo peculiar que lidam com as interferências do ambiente social, processando-as em seu interior dentro das limitações impostas por sua própria forma de comunicação, uma vez que o sistema aceita a interferência externa, desde que possa ser compreendida por seu código binário, e a processa internamente mantendo a sua função ou essência, ou seja, as interferências são processadas em seu interior e podem tornar o sistema mais complexo, mas a forma de se comunicar, isto é, seu código binário, é mantida e o sistema mantem as características que o diferenciam dos demais sistemas e do ambiente.

Conforme Duarte, Cademartori e Baggenstoss (2012, p. 240), a teoria dos sistemas sociais autopoiéticos tem como características a diferenciação dos sistemas por sua linguagem binária, que no Direito utiliza o código lícito/ilícito, jurídico/antijurídico ou direito/não direito, sendo que, "para a evolução do sistema jurídico e, por conseguinte, a sua correspondência com o meio em que se insere (sistema social), a sua referência interna deve obedecer ao mecanismo de fechamento operacional", por meio do fechamento operacional e, ao mesmo tempo, abertura cognitiva com o ambiente e demais sistemas, selecionando as informações dos demais sistemas e/ou ambiente que são suportados pela estrutura do sistema.

A teoria dos sistemas autorreferenciais, para Luhmann (2016b, p. 25), consiste no fato que a "diferenciação de sistemas somente pode ocorrer mediante autorreferência, quer dizer, somente porque os sistemas na constituição de seus elementos e de suas operações elementares se referem a si mesmos", referência esta que pode ocorrer em relação aos elementos do mesmo sistema, às suas operações ou à sua unidade. Os sistemas autorreferenciais produzem relações consigo mesmos e possuem a capacidade de diferenciar estas relações do seu ambiente ${ }^{5}$.

Esta diferenciação entre sistemas (LUHMANN, 2016b, p. 25-26) depende da capacidade do sistema produzir e empregar uma descrição de si mesmo ou pelo menos de empregar uma diferenciação entre si e o ambiente e de como as informações do ambiente são processadas no interior do sistema, sendo que "os sistemas têm de conseguir lidar com a diferença entre identidade e diferença, quando se reproduzem como sistemas autorreferenciais; ou, dito de outro modo: reprodução é o manejo dessa diferença" (LUHMANN, 2016b, p. 25-26).

A teoria geral dos sistemas advinda da sociologia possibilita, então, uma análise dos sistemas sociais de forma mais abstrata, com a construção de um conceito de sistema que pode ser aplicado aos diversos sistemas sociais, de forma interdisciplinar (LUHMANN, 2016b, p. 28), adotando-se como foco as relações entre sistemas e ambiente e as comunicações entre sistemas distintos, que interferem no interior dos sistemas e possibilitam que se autorreproduzam.

É importante, ainda, compreender o Direito como um sistema social autorreferencial para que seja possível distingui-lo dos demais sistemas sociais e delimitar a sua funcionalidade, notadamente para a compreensão de suas relações com o subsistema político e suas interferências nas atribuições dos demais poderes.

O direito como subsistema autorreferencial, segundo Luhmann (2016a, p. 184), decorre do fato que ele jamais se inicia, embora evolua a forma de lidar com as questões em razão das mudanças sociais, mantendo sua funcionalidade fechada (código lícito/ilícito), pois "se a sociedade possibilita a sua diferenciação, o direito se fecha em um sistema autorreferencial e trabalha com o material normativo que sempre esteve à sua disposição" (LUHMANN, 2016a, p. 184).

A mudança é provocada por uma interferência externa, do ambiente (sociedade), mas o seu processamento é sempre interno e limitado às características operacionais do próprio sistema, de modo que o sistema do direito mantém sua diferenciação em relação ao ambiente e aos demais sistemas.

\footnotetext{
${ }^{5}$ Não é possível concordar com a afirmativa de inexistência de interferência entre os subsistemas, tendo em vista que a diferenciação ocorre mediante autorreferência. É como o subsistema se distingue dos demais e é isso que possibilita a sua existência como um todo. No entanto, os subsistemas, ainda assim, interferem mutuamente uns nos outros, como será demonstrado mais adiante.
}

Revista de Direito Brasileira | Florianópolis, SC | v. 24 | n. 9 | p.120-136 | Set./Dez. 2019 
A característica marcante do sistema do direito é o fato de trabalhar com a linguagem binária legal/ilegal (lícito/ilícito ou jurídico/antijurídico), cabendo aqui ressalvar que esta linguagem binária aplicada ao Direito pressupõe um sistema jurídico positivado, conforme destaca Luhmann (2016a, p. 222-223).

A linguagem binária possibilita, portanto, que o sistema do direito se diferencie dos demais sistemas, além de limitar as interferências do ambiente, internalizando somente as questões assimiláveis e pertinentes à discussão do lícito/ilícito. Por outro lado, esta diferenciação não torna imutável o sistema, que se mantém operacionalmente fechado, embora possibilite que as alterações ocorram internamente, mantendo-se as bases de sua estrutura.

Isto possibilita a evolução do sistema sem que perca sua função normativa, conforme Luhmann:

No sentido temporal, o direito tem que ser institucionalizado como sendo modificável, sem que isso limite sua função normativa. Isso é possível. A função de uma estrutura não pressupõe uma constância absoluta, mas apenas exige que a estrutura não seja problematizada nas situações por ela estruturadas. Isso permite que em outras situações (em outros momentos, para outros papéis ou outras pessoas) ela se torne objeto de decisão, ou seja, variável. O que é necessário é apenas uma delimitação claramente perceptível e firmemente institucionalizada, que destaque essas situações. A positivação do direito consiste em um tratamento contraditório das estruturas com base na diferenciação dos sistemas (LUHMANN, 1985, p. $10)$.

Luhmann (1985, p. 27-30) considera que o direito positivado, em sua aplicação, torna-se uma programação decisória, por meio do condicionamento das normas jurídicas, distanciando-se de conceitos principiológicos. Estabelece-se uma expectativa condicional de relação se/então, em que um conjunto de fatos leva a determinadas consequências jurídicas, cuja execução configura um ato decisório. Este condicionamento reduz a complexidade da aplicação do direito a uma estrutura binária, bipolar, que alterna da condição 'se' para a consequência 'então', permitindo a aplicação de uma solução para casos análogos.

Se a redução da complexidade do ambiente ao código lícito/ilícito possibilita ao direito internalizar as demandas e processá-las de forma mais objetiva, evitando que as decisões judiciais tenham que lidar com uma infinitude de variáveis sobre as causas e os efeitos dela decorrentes, por outro lado haverá uma limitação das consequências ${ }^{6}$. Segundo Luhmann:

Um caso especial desse desafogamento merece considerações especiais: o desafogamento da atenção e da responsabilidade com respeito às consequências da decisão. É necessário reconhecer que o estilo da decisão jurídica submetida a programações condicionais implica necessariamente que junto com o "se" estatui-se também o "então", aceitando suas consequências sem calculá-las ou valorá-las (LUHMANN, 1985, p. 31).

O Direito trabalha, portanto, com o código binário lícito/ilícito e utiliza informações internas, baseadas em normas ou precedentes judiciais, para dar soluções aos casos submetidos à sua apreciação, utilizando como origem a lógica pela qual determinado problema terá sempre uma solução específica, cuja resposta do Poder Judiciário é impositiva.

\footnotetext{
${ }^{6}$ Aqui aparece o que Luhmann (2016a) menciona a função do Direito de "estabilizar expectativas", a partir da questão das incertezas.
} 
Para Barroso (2014, p. 254), “[...] a atribuição típica do Poder Judiciário consiste na aplicação do direito a situações em que tenha surgido uma disputa, um litígio entre as partes [...]", caracterizando-se pela atuação de forma técnica na interpretação da lei e aplicação ao caso concreto.

Ocorre que a limitação provocada pela programação condicionante do código lícito/ilícito também implica em "renúncia à responsabilidade pelas consequências", conforme Luhmann (1985, p. 33), o que é alvo de críticas quando se analisa a atuação do Poder Judiciário na implementação de políticas públicas.

Luhmann prevê, contudo, que o Direito, ao lidar com a complexidade do ambiente, pode também se auto modificar por meio da autopoiese e, com isso, absorver questões mais complexas na medida em que o próprio subsistema do Direito se torna mais complexo. Nesse sentido, propõese, então, que o Direito trabalhe também de forma a revisar os programas condicionais:

A solução é encontrada no próprio princípio da positividade do direito: na possibilidade de decidir-se também quanto aos programas decisórios. Isso permite diferenciar entre decisões programadoras e decisões programadas e prever, para os respectivos processos decisórios, requisitos e condições diferentes ou até mesmo opostas. Dessa forma torna-se ainda possível corrigir a unilateralidade da perspectiva dos programas condicionais por meio da consideração de princípios inversos - ao decidir-se politicamente, segundo critérios de oportunidade, sobre a promulgação ou mudança de programas condicionais (LUHMANN, 1985, p. 33).

Pode-se concluir, portanto, que o subsistema do Direito está em constante evolução, como os demais subsistemas sociais, mas mantém como característica a sua operação por meio do código lícito/ilícito, que, embora não impeça a assimilação das informações trazidas pelo ambiente e demais subsistemas, possibilita que o subsistema jurídico se torne mais complexo à medida em que assimila a evolução do sistemas social e dos outros subsistemas com os quais se inter-relaciona.

\section{DISTINÇÃO FUNCIONAL ENTRE DIREITO E POLÍTICA}

O Estado de Direito, ao impor que as ações políticas se conformem à estrutura normativa, acaba por aproximar os subsistemas jurídico e político de tal forma que torna difícil a sua distinção. Luhmann (2016a, p. 558) atenta para o equívoco por vezes estabelecido no sentido de que Direito e Política consistiriam em um mesmo subsistema, diante de suas coincidências e da inter-relação estabelecida com o advento do Estado de Direito, que pressupõe a unidade entre política e direito.

O sistema irá responder à irritação gerada pelo ambiente/sociedade e terá uma resposta distinta conforme o padrão de operação do sistema. Sobre o tema, Fornasier e Rogerio discorrem:

Nesse sentido, no sistema social funcionalmente diferenciado é possível que cada subsistema se organize e se autodescreva de acordo com seu próprio código em relação aos assuntos que envolvem a construção de hidrelétricas. O sistema jurídico, por exemplo, pode evoluir com a irritação da comunicação dos demais subsistemas e formular novas decisões; o sistema político pode se irritar e evoluir editando novas normas; o sistema econômico, para evoluir, pode se irritar de modo a perceber as novas oportunidades de mercado e o sistema da ciência é irritado quando percebe que uma comunicação científica antes verdadeira, pode ser declarada falsa (FORNASIER; ROGERIO, 2018, p. 168). 
Estas alterações são provocadas pelo ambiente (sociedade) que ao demandarem prestações de serviços públicos diretamente frente ao Poder Judiciário acabam por irritar o sistema, trazendo a linguagem da política para dentro do Poder Judiciário.

Quando a sociedade demanda a realização de uma política pública junto ao Poder Judiciário há uma alteração do subsistema do Direito em razão das interações/interferências entre Poder Judiciário, Poder Executivo e ambiente/sociedade. O Poder Judiciário deve processar as informações do ambiente e se adaptar para, mantendo as condições binárias de comunicação baseadas no lícito/ilícito ${ }^{7}$, adequar-se ao sistema constitucional da separação dos poderes e, ainda assim, atuar na efetivação de direitos fundamentais cujas políticas públicas se revelaram insuficientes.

A CR/88 é o acoplamento estrutural entre estes sistemas sociais e consiste no elemento de conjugação entre Direito e Política ao permitir o diálogo entre o lícito/ilícito e a poder/não-poder, com mútua influência entre os sistemas.

Para Luhmann (2016a, p. 560), não se pode condicionar a política a uma interpretação pré-fixada do texto constitucional, embora as metas políticas devam buscar o alcance do texto constitucional. Do mesmo modo "não se chega a nenhuma teoria acertada do sistema jurídico quando o que realmente acontece é concebido como implementação de programas políticos, por mais que as decisões jurídicas se orientem para consequências políticas desejadas" (LUHMANN, 2016a, p. 560).

O direito, portanto, lida com questões judicializáveis, não cabendo a ele investigar soluções que viabilizem uma melhor qualidade de vida para os cidadãos e, então, realizar as políticas públicas necessárias.

Giorgi (2007, p. 38) afirma que o "direito exclui de si o que não é direito, mas exclui também valorações, interesses, condições, status, eventos que não são tratados como juridicamente relevantes". Barroso afirma que:

Juízes não criam o direito nem definem as ações administrativas. Seu papel é aplicar a Constituição e as leis, valendo-se de um conjunto de institutos consolidados de longa data, sendo que a jurisprudência desempenha um papel limitador dessa atuação, pela vinculação aos precedentes. Direito e política, nessa visão, constituem mundos apartados (BARROSO, 2014, p. 261).

Luhmann destaca que a separação dos subsistemas jurídico e político decorre principalmente de sua codificação:

O esquema governo/oposição torna-se a 'forma', o 'código' do sistema político no sentido de que a forma tem um lado interno e o código tem um lado positivo, capaz de enlace, onde a ação está. Contudo, o lado interno da forma só é o que é por haver o outro lado, onde alternativas se encontram disponíveis. Já no sistema jurídico as alternativas são tratadas de modo bem diferente. Elas são e se mantêm dispersas e dependentes de casos e regras individuais, não havendo o menor rudimento de uma 'oposição consolidada'. E, ainda que ela existisse, não seria reconhecida como forma do direito, mas como forma da política (LUHMANN, 2016a, p. 564-565).

\footnotetext{
${ }^{7}$ Destaca-se que as condições binárias são elementos para obstar a alteração do subsistema que só se modificará se o código tornar-se outro; caso contrário, mantem-se o subsistema do Direito sem alteração. Sem embargo, o problema acontece quando o subsistema jurídico começa a trabalhar com a linguagem de outros subsistemas (alopoiese ou corrupção sistêmica), o que será analisado na última parte deste estudo.
}

Revista de Direito Brasileira | Florianópolis, SC | v. 24 | n. 9 | p.120-136 | Set./Dez. 2019 
Essa distinção entre os subsistemas jurídico e político não afasta a relação entre eles, bem como a interdependência decorrente do acoplamento estrutural ${ }^{8}$, que no Estado de Direito se dá por meio da $\mathrm{CR} / 88$, a qual possibilita a "suspensão jurídica do poder político e a instrumentalização política do direito" (LUHMANN, 2016a. p. 565).

No mesmo sentido lecionam Duarte, Cademartori e Baggenstoss (2012, p. 240), quando afirmam que "a Constituição, por consequência, manifesta-se como acoplamento estrutural e determina o comportamento dos órgãos jurisdicionais e, por isso, os limites conteudísticos das decisões produzidas pelo sistema $[\ldots]$ ”.

É importante que se compreenda, ainda, como os subsistemas do Direito e da Política lidam com a questão da complexidade e contingência, que constituem aspectos fundamentais da Teoria dos Sistemas Sociais Autopoiéticos.

Complexidade e contingência são conceitos irmãos e, enquanto complexidade se opõe à ideia de simplicidade, pois sempre haverá uma pluralidade de opções, comportando, para uma determinada situação fática, inúmeras soluções, a contingência remete à ideia que se há várias opções, uma situação comporta uma pluralidade de resultados, com maiores ou menores probabilidades, mas não se poderá cogitar um resultado pré-determinado.

Conforme Duarte, Cademartori e Baggenstoss (2012, p. 243), na medida em que o sistema interage com o ambiente e "gera probabilidades relacionais, mas em razão menor que o seu ambiente, que é sempre mais complexo por conter um número maior de elementos", ocorre um aumento de "desordem e contingência, e, por consequência, faz com que o sistema selecione apenas algumas possibilidades que lhe fazem sentido de acordo com a função que desempenha [...]". Para Fornasier e Rogério:

Em uma sociedade hipercomplexa, na qual um fato social pode ser interpretado de várias maneiras, a policontexturalidade é um elemento que representa o pluralismo de perspectivas conflitantes entre sistemas, reforçando a ideia de que a realidade pode ser observada sob pontos de vista diferentes e que não é adequado eleger um ponto de vista como sendo o correto ou o superior perante os demais. Essa é uma característica que diferencia a teoria dos sistemas autopoiéticos das demais porque ela aponta os fenômenos para a diferença e não para a identidade social (FORNASIER E ROGERIO, 2018, p. 186).

$\mathrm{Na}$ contemporaneidade é preciso partir da ideia de que o mundo possui relações infinitas e complexas e de um mesmo fato poderão decorrer inúmeros resultados, sendo que a análise do direito sob a matriz sistêmica implica em aceitar que não há uma única decisão que pode ser préestabelecida com base em valores naturais da essência humana ou da natureza. Schwartz e Santos Neto:

Com o uso da fórmula da contingência, pode-se refutar o conceito jusnaturalista de justiça. A própria natureza não é justa. Inexiste inferência que vá do 'natural' ao 'justo'. Como resultado da evolução, pode existir um equilíbrio da natureza. No Direito, poderia ser dito, a prática jurídica está ajustada de acordo com uma quantidade normal de querelas e disputas. Mas não se pode concluir disto que a ordem jurídica seja justa. A ordem é um resultado fático da evolução. A teoria sistêmica da evolução descreve e explica o fato de que um sistema autopoiético, determinado estruturalmente, possa alterar suas próprias estruturas e a forma de realizar

\footnotetext{
${ }^{8}$ Justifica-se essa afirmação porque a distinção funcional entre direito e política se mantem íntegra na CR/88, embora seja difícil estabelecer a distinção entre os subsistemas, conforme apresentado no em momento anterior neste apartado.
}

Revista de Direito Brasileira | Florianópolis, SC | v. 24 | n. 9 | p.120-136 | Set./Dez. 2019 
suas operações, recorrendo ao esquema de observação que utiliza as três categorias de: a) variação; b) seleção (de variações) e c) estabilização (SCHWARTZ; SANTOS NETO, 2009, p. 38).

O subsistema do Direito tem como função principal, portanto, conforme Duarte, Cademartori e Baggenstoss (2012, p. 248), "“...] generalizar e estabilizar expectativas de condutas e regular conflitos mediante a constituição de procedimentos para fazê-lo".

Por sua vez, o subsistema político tem de lidar com o código operacional poder/não poder ou posição/oposição (LUHMANN, 2016a, p. 447-448) e tem como objetivo implementar programas por meio de decisões coletivamente vinculativas, cujos resultados serão mais ou menos prováveis e não vinculados como ocorre com o subsistema jurídico. Nesse sentido discorrem King e Tornhill ${ }^{9}$ :

Este também é o caso do sistema político, que, de acordo com Luhmann, resulta da diferenciação de um sistema particular de comunicações, cuja função única é a produção de uma ligação coletiva decisões. Como tal, o sistema político é o sistema de funções da moderna sociedade que fornece poder como um recurso universal. É, portanto, o sistema que impõe decisões em questões cujas implicações se estendem além dos limites de um ou outro sistema, e que então criam acoplamentos problemáticos entre sistemas distintos (KING; TORNHILL, 2003, p. 70).

O Poder Executivo, quando implementa uma política pública, pratica determinadas ações com a intenção de alcançar um resultado provável, sem que se possa prever que uma determinada ação resultará sempre em um resultado específico. Se as opções quanto à forma de agir são múltiplas, os resultados também serão alcançados de acordo com a escolha da forma de realização da política pública e pode ser alcançado, com maior ou menor probabilidade, a depender de inúmeros fatores externos.

Na política, o subsistema tem de lidar com a complexidade das relações de poder e realizar opções que atendam ao interesse público mediante juízos de probabilidade.

Não se pode desconsiderar, ainda, que os subsistemas estão em constante evolução, conforme Fornasier e Rogerio:

O modelo de sociedade moderno observado pela teoria social de Luhmann apresenta como característica a dinâmica temporal, ou seja, concepções até então consideradas inabaladas e estáveis podem ser modificadas conforme a dinâmica social. $\mathrm{O}$ fato de a sociedade ser funcionalmente diferenciada permite que uma nova percepção social seja compreendida através da observação de segunda ordem - a realidade pode ser verificada a partir de vários pontos de vista diferentes. Nesse sentido, a Política, assim como o Direito, a Economia e a Ciência, devem ser repensados (FORNASIER; ROGERIO, 2018, p. 196).

As relações e interferências geradas entre o Direito, a Política e a sociedade tornam-se ainda mais complexas nos tempos atuais, marcados pelo pluralismo e fluidez das relações, o que tem demandado maior processamento de informações pelos sistemas e maior complexidade em seu interior para lidar com questões que antes lhe eram exteriores.

${ }^{9}$ Tradução livre do autor.

Revista de Direito Brasileira | Florianópolis, SC | v. 24 | n. 9 | p.120-136 | Set./Dez. 2019 

ultraciclo:

Nesse sentido, Fornasier e Rogerio destacam as formas de interações dos sistemas por

A noção de ultraciclo opera para além do sistema interno. Ocorre quando um ciclo de pressões distintas e mútuas surge entre sistemas fechados e entre ordenamentos de naturezas diferentes, propiciando a mudança de perspectiva. Juntamente com esta mudança, as pressões de aprendizado são as mais notórias, pois permitem que ocorram alterações intrassistêmicas provocadas por irritações extrassistêmicas (a interação por ultraciclo possibilita a observação entre sistemas de abertura mútua, mesmo que entre sistemas fechados operativamente) (FORNASIER; ROGERIO, 2018, p. 188).

É o que se verifica quando os subsistemas jurídico, político, social e econômico se relacionam interferindo mutuamente e os subsistemas passam a operar parcialmente com a utilização do código operacional de outros subsistemas, colocando em dúvida a manutenção de sua funcionalidade.

Assim, torna-se importante analisar a ideia de corrupção sistêmica, que ocorre quando um subsistema interfere de forma a se sobrepor ao outro, retirando a sua própria funcionalidade, o que poderia resultar em uma patologia social.

\section{POLÍTICAS PÚBLICAS E CORRUPÇÃO SISTÊMICA}

Os elementos distintivos entre os subsistemas sociais do Direito e da Política expostos anteriormente trazem substrato para uma análise crítica acerca das interferências do Poder Judiciário na realização de políticas públicas por parte do Poder Executivo, provocadas por crescente demanda social pela implementação de direitos fundamentais constitucionalmente assegurados.

Esta atuação mais ativa do Poder Judiciário é marcada pela superação do positivismo e ampara-se em teorias que propõem interpretação mais ampla do texto constitucional, atribuindo ao Poder Judiciário a condição de protagonista na proteção de direitos fundamentais.

Barroso (2014, p. 190-191) afirma que o neoconstitucionalismo no Brasil teve como marco histórico o renascimento do Direito Constitucional com a redemocratização do país após anos de regime autoritário, que perdurou de 1964 a 1985, culminando com a CR/88 a qual possibilitou o surgimento de um ambiente de estabilidade institucional.

Como marco filosófico, Barroso (2014) atribui ao pós-positivismo, com a superação do jusnaturalismo e do positivismo, o surgimento de uma nova teoria do Direito, afirmando que "a superação histórica do jusnaturalismo e o fracasso político do positivismo abriram espaço para um conjunto amplo ainda inacabado de reflexões acerca do Direito, de sua função social e sua interpretação" (BARROSO, 2014, p. 192). Esta nova forma de pensar o direito, segundo Barroso (2014, p. 192-193), possibilitou a adoção de uma "teoria de justiça" na interpretação e aplicação do Direito, utilizando-se como referência alguns instrumentos como:

[...] a atribuição de normatividade aos princípios e a definição de suas relações com valores e regras; a reabilitação da razão prática e da argumentação jurídica; a formação de uma nova hermenêutica constitucional; e o desenvolvimento de uma teoria dos direitos 
fundamentais edificada sobre o fundamento da dignidade da pessoa humana (BARROSO, 2014, p. 193) ${ }^{10}$.

Quanto ao marco teórico do neoconstitucionalismo brasileiro, Barroso (2014, p. 193-201) atribui a três fatores que transformaram a hermenêutica constitucional:: I- a atribuição de força normativa aos princípios constitucionais; II- o crescimento da jurisdição constitucional; e III- o incremento de uma nova hermenêutica constitucional.

Há que se ponderar, contudo, que a expansão do constitucionalismo tem como um de seus efeitos a ascensão do Poder Judiciário, cuja competência para interpretar e aplicar a CR/88 acaba por interferir nos demais Poderes e resulta numa crescente judicialização de questões antes restritas ao campo político.

Para Barroso (2014, p. 39-40) o protagonismo do Poder Judiciário e o ativismo judicial surgidos com o novo constitucionalismo no Brasil, que acabam por transferir Poderes do Executivo e Legislativo ao Judiciário, têm como fatores preponderantes: I- o reconhecimento da importância do Poder Judiciário para a garantia de direitos fundamentais; II- a desilusão da sociedade com a política majoritária; III- a preferência de atores políticos pela via judicial para a resolução de questões polêmicas, como o aborto ou o direito de homossexuais, que poderiam gerar desgaste político. Soma-se a isso o fato da CR/88 tratar de uma quantidade enorme de temas, fato que, segundo Barroso (2014, p. 39), retira a questão do plano político para incluí-la na esfera do Direito, permitindo a sua judicialização.

Assim, Barroso (2014, p. 244) defende que "[...] a judicialização constitui um fato inelutável, uma circunstância decorrente do desenho institucional vigente, e não uma opção política do Judiciário".

Como fato inelutável e intrínseco à democracia moderna, a atuação do Poder Judiciário na esfera política é defendida por Pogrebinschi (2012, p. 179-181), para quem a representação política não deve se limitar a aspectos eleitorais ou critérios de maioria, mas à capacidade das instituições políticas de atuarem, na prática, na defesa de interesses de determinado seguimento social, como se verifica em relação às Cortes Superiores e sua aptidão para a proteção de interesses contra majoritários.

A atuação política do Poder Judiciário, contudo, deve ser vista de forma crítica, para que sejam observados determinados parâmetros, evitando-se que a exceção se torne regra, com a sobreposição do Poder Judiciário sobre os demais poderes ${ }^{11}$.

Roach (2001, p. 329-330) destaca a importância da realização de uma crítica fundamentada sobre o ativismo judicial, que não deve se limitar a atacar a liberdade dos magistrados na interpretação do texto constitucional, posto que esta função é inerente ao Poder Judiciário.

Por esta razão, a visão sistêmica tem muito a contribuir para a análise dos limites da atuação judicial na realização de políticas públicas.

Canotilho (2010, p. 30) ressalta a importância da razoabilidade e racionalidade na atuação do Poder Judiciário para assegurar direitos fundamentais quando ressalta que, embora os tribunais não devam ficar alheios "à concretização judicial das normas directoras da constituição social", também não pode impor-se a metódica constitucional a criação de pressupostos de facto e de direitos claramente fora de sua competência ou extravazando os seus limites jurídico-funcionais". Assim, a manutenção do próprio direito fundamental dependeria de níveis adequados e proporcionais de prestações judiciais.

\footnotetext{
${ }^{10}$ Para aprofundamento nas dimensões do desenvolvimento sustentável, especialmente na dimensão jurídico política como forma de se assegurar os direitos fundamentais intergeracionais e sua relação com as políticas públicas, ver respectivamente: GOMES; FERREIRA, 2017, p. 94-105 e GOMES; FERREIRA, 2018, p. 161-172.

${ }^{11}$ Para aprofundamentos em tal afirmação, ver: SOUZA; GOMES, 2015, p. 15-154.
} 
É nesse sentido que Sunstein (2008, p. 186-191) critica a atuação do Poder Judiciário para implementar mudanças sociais por meio da conformação de políticas públicas, quando destaca que a dependência de decisões políticas por parte das Cortes pode levar ao comprometimento da cidadania, com restrição da participação popular, além de ser questionável a própria eficácia das decisões judiciais que buscam implementar mudanças sociais e a limitação dos magistrados para compreenderem os efeitos complexos e imprevisíveis da decisão judicial.

Uma crítica apresentada ao ativismo judicial por Barroso (2014) e que merece destaque refere-se à capacidade institucional e aos efeitos sistêmicos:

Capacidade institucional envolve a determinação de qual Poder está mais habilitado a produzir a melhor decisão em determinada matéria. Temas envolvendo aspectos técnicos ou científicos qualificado podem não ter no juiz de direito o árbitro mais qualificado, por falta de informação ou de conhecimento específico. Também o risco de efeitos sistêmicos imprevisíveis e indesejáveis podem recomendar uma posição de cautela e de deferência por parte do Judiciário. O juiz, por vocação e treinamento, normalmente estará preparado para realizar a justiça do caso concreto, a microjustiça, sem condições, muitas vezes, de avaliar o impacto de suas decisões sobre um segmento econômico ou sobre a prestação de um serviço público (BARROSO, 2014, p. 249).

Cumpre destacar, ainda, a crítica quanto à limitação do debate quando a questão é judicializada, sendo que "a primeira consequência drástica da judicialização é a elitização do debate e a exclusão dos que não dominam a linguagem nem têm acesso aos locus de discussão jurídica [...]" (BARROSO, 2014, p. 50). Quanto a limitação “[...] a transferência do debate público para o Judiciário traz uma dose excessiva de politização dos tribunais, dando lugar a paixões em um ambiente que deve ser presidido pela razão" (BARROSO, 2014, p. 250).

Assim, a separação entre direito e política se mostra imprescindível para o Estado constitucional democrático, reservando-se ao direito a imperatividade da lei e à política a soberania da vontade popular.

É preciso compreender os riscos decorrentes da sobreposição de um subsistema sobre o outro, muitas vezes movida por movimentos que se iniciam na sociedade e que demandam do Direito soluções que não podem ser alcançadas somente por meio dele, como ressalva Campilongo:

Acreditou-se, com ardor, no Direito como instrumento de transformação social, especialmente após a promulgação da Constituição de 1988. Mas sempre houve, também, quem fosse descrente dessa capacidade e, com boas razões empíricas, visse no Direito um obstáculo às mudanças. Os dois extremos são equivocados: superdimensionam a função do Direito. $\mathrm{O}$ Direito não determina nem controla o ambiente que o circunda: é incapaz de tomar o lugar, funcional e operacionalmente, da saúde, da educação, da economia ou da política. A recíproca é verdadeira: os sistemas sanitário, educativo, econômico, e político também não suprem o que é típico e exclusivo da comunicação jurídica (CAMPILONGO, 2012, p. 234).

Ultrapassar os limites funcionais de um subsistema social sem a análise da proporcionalidade e adequação das medidas, ou seja, da necessidade de interferência mútua dos subsistemas e dos limites em que estas interferências se mostrem saudáveis para o sistema social de forma ampla, implica no risco de interferência e colapso do próprio sistema, conforme adverte Campilongo: "os riscos de confusão e indistinção entre o que é próprio do sistema jurídico e o que 
é típico dos demais sistemas é maximizado. Exige-se do Direito algo impossível de ser oferecido. O resultado é o bloqueio mútuo das operações do sistema jurídico e dos demais sistemas" (CAMPILONGO, 2012, p. 234).

Em uma análise fundada na teoria dos sistemas sociais, a interferência excessiva entre os subsistemas, de forma crônica, pode levar à corrupção sistêmica, conforme leciona Neves:

Esse problema relaciona-se com o fato de que ao código primário e aos critérios de um sistema sobrepõem-se os códigos e critérios de outros sistemas, ou uns bloqueiam os outros, do que resulta uma miscelânea social de códigos e critérios em detrimento da diferenciação funcional. A esse respeito, o conceito de corrupção sistêmica ocupa lugar destacado (NEVES, 2012, p. 202).

$\mathrm{O}$ enfraquecimento de um subsistema em detrimento do protagonismo do outro subsistema, portanto, pode ocasionar o bloqueio da função de um dos subsistemas e prejudicar o equilíbrio dos subsistemas sociais.

Isto não significa que um subsistema não possa interferir no outro e, eventualmente, influenciar determinadas funções, assim como o ambiente também interfere nas funções do subsistema. Esta interferência pontual contribui para a complexidade interna do subsistema, que ao absorver informações de outros subsistemas e do ambiente promove sua própria evolução, que é a ideia da autopoiese. Para Duarte, Cademartori e Baggenstoss:

Essa evolução é condicionada às interferências/irritações do ambiente, que podem levá-lo à transformação de suas estruturas conforme a tolerância do sistema. Aqui, retoma-se a ideia de autopoiese: a produção de si mesmo, responsável por um aumento constante de possibilidades até que a complexidade atinja limites não tolerados pela estrutura do sistema, leva-o a mudar sua forma de diferenciação. A evolução do sistema ocorre quando ele se autodiferencia e ainda quando há uma passagem de um tipo de diferenciação para outro (DUARTE; CADEMARTORI; BAGGENSTOSS, 2012, p. 244).

É necessário diferenciar a interferência ou irritação comedida dos subsistemas, que não alteram suas funções, mas apenas o tornam mais complexos e compatíveis com a evolução da sociedade, das interferências desmedidas, muitas vezes ocasionadas por disfunções do próprio sistema social no qual os subsistemas jurídico e político estão inseridos.

A corrupção sistêmica momentânea, tolerável pelo sistema, deve ser distinguida da corrupção crônica, que acaba por afetar as funções dos subsistemas e desvirtua o acoplamento estrutural, que no caso dos subsistemas jurídico e político decorre da CR/88. Nesse sentido, Neves destaca:

Uma corrupção sistêmica é apenas operativa quando ela é momentânea e, portanto, só atinge uma ou algumas operações. Nesse caso, ele tem efeitos simplesmente sobre os acoplamentos operativos entre os sistemas funcionais da sociedade. Em muitas situações, a redundância e a durabilidade da corrupção conduzem à formação de estruturas de expectativas, de tal maneira que tanto cognitiva quanto normativamente não se pode expectar, com segurança, no correspondente contexto, outra coisa, senão a atividade corrupta. Nesse caso, a corrupção sistêmica afeta os acoplamentos estruturais entre sistemas funcionais e, igualmente, a 
autonomia desses, sendo dependente das organizações (NEVES, 2012, p. 203).

As críticas ao ativismo judicial mostram-se válidas, portanto, na medida em que buscam uma análise da limitação do Poder Judiciário às funções que o texto constitucional o reservou, pois embora lhe seja atribuída a proteção a direitos fundamentais consagrados no texto constitucional, a atuação, sem a devida reflexão e por meio de técnica inadequada, sobretudo porque o Poder Judiciário não possui a estrutura necessária e conhecimentos técnicos específicos, por exemplo, para a realização de políticas públicas, poderá acabar por inviabilizar o próprio direito que se buscou proteger.

É imprescindível para a compreensão do tema que se faça uma reflexão de forma global do sistema de proteção aos direitos fundamentais, assegurando-se que a interferência entre os subsistemas político e jurídico não acabem por inviabilizar a atuação de algum deles, cujos danos, em caso de colapso ou anulação funcional, poderiam ser ainda maiores para a sociedade.

A crítica tecida por Canotillo merece destaque neste ponto, quando discorre sobre o ativismo em favor dos desfavorecidos:

Temos manifestado as mais sérias reticências a esse activismo, por mais nobre que seja a sua intencionalidade solidária. Além de se limitarem a sentenças casuísticas - sobretudo no âmbito de prestações de saúde - faltalhes legitimidade para a apreciação político-judicial das desconformidades constitucionais das políticas públicas. Neste contexto, parecem-nos mais politicamente eficazes as manifestações públicas de 'cidadãos difíceis' contra as políticas da saúde ou contra as políticas ambientais do que o sistemático recurso ao Poder Judiciário (CANOTILLO, 2010, p. 35).

A análise da interferência do Poder Judiciário nas políticas públicas realizadas pelo Poder Executivo demanda, portanto, uma compreensão global do funcionamento dos subsistemas e de suas funções, para que o objetivo de assegurar um direito fundamental previsto no texto constitucional não tenha como efeito transverso o prejuízo a outros direitos fundamentais ou ao próprio direito que se busca resguardar.

\section{CONSIDERAÇÕES FINAIS}

O presente trabalho permite considerar que o Direito constitui um subsistema Social autopoiético, capaz de se diferenciar dos demais subsistemas em razão de sua estrutura funcional, que atua por meio da linguagem jurídico/antijurídico ou lícito/ilícito.

Assim como os demais subsistemas sociais autopoiéticos, o Direito se mantém como subsistema distinto ao diferenciar-se do ambiente e dos demais subsistemas, embora esta diferenciação não impossibilite a alteração/evolução do subsistema internamente, pois ao receber interferências externas o subsistema se mantém operacionalmente fechado, mantendo a sua estrutura funcional, mas permanece aberto cognitivamente.

A abertura cognitiva permite que o sistema social se autoproduza e, por ser sempre menos complexo que o ambiente, as interferências externas constituam um aumento constante de possibilidades que tornam o sistema mais complexo até que os limites da complexidade não sejam tolerados pela estrutura do sistema, alterando a sua forma de diferenciação.

Para que se mantenha como subsistema distinto, portanto, o Direito deve se limitar à sua função principal que é, utilizando o poder de decidir questões concretas por meio do código lícito/ilícito, estabilizar as expectativas do ambiente social. 
Por outro lado, o subsistema político lida com a linguagem poder/não poder ou situação/oposição e tem como objetivo a edição de decisões vinculantes que conduzem à melhoria das condições de vida da sociedade, mas diversamente do subsistema jurídico, as ações políticas não estão voltadas para decisões que vinculem comportamentos e que, de forma impositiva, conduzem a uma consequência preestabelecida.

O subsistema político tem de lidar com a complexidade e contingência da sociedade de forma mais aberta, de modo que as decisões são tomadas buscando uma solução provável. Quando o Poder Executivo realiza uma política pública, as decisões buscam sempre uma finalidade provável, mas não há como vincular suas ações a um resultado específico, o juízo é sempre de maior ou menor probabilidade.

Verifica-se, assim, que os subsistemas político e jurídico, embora acoplados estruturalmente pela Constituição do Estado, lidam de forma diversa com as demandas do ambiente social que envolvam a tutela de direitos fundamentais.

No subsistema jurídico, a redução da complexidade do ambiente ao código lícito/ilícito possibilita a internalização das demandas e o seu processamento de forma mais célere, buscando a estabilização de expectativas de forma mais objetiva, mas por outro lado haverá uma limitação substancial das consequências.

O subsistema político, por sua vez, permite uma maior compreensão do ambiente e da ponderação de meios necessários à efetivação de direitos fundamentais, mas as soluções são tratadas em médio e longo prazo, o que resulta em insegurança para o ambiente social.

As interferências mútuas entre estes subsistemas sociais possibilitam, assim, por meio do acoplamento estrutural, que os subsistemas se tornem mais complexos ao assimilarem as informações do outro subsistema, embora se corra o risco de, em casos de interferências desmedidas e duradouras, um subsistema se sobrepor ao outro e levar ao prejuízo de suas funções, gerando a corrupção sistêmica.

Nesse sentido, mostram-se relevantes as críticas ao ativismo judicial e à atuação excessiva do Poder Judiciário na realização de políticas públicas que, embora tenham o objetivo de assegurar um direito fundamental previsto no texto constitucional, podem resultar na sobreposição das funções de um subsistema sobre o outro e desencadear a corrupção sistêmica, que poderia inviabilizar o próprio direito que se pretendia tutelar.

É preciso, portanto, compreender as relações intersistêmicas de forma global e não casuística, de modo que os subsistemas jurídico e político possam se relacionar e contribuir para a evolução do outro subsistema, aumentando sua complexidade interna para lidar com o ambiente social, mas sem perder sua capacidade funcional.

\section{REFERÊNCIAS}

BARROSO, Luís Roberto. O novo direito constitucional brasileiro: contribuições para a construção teórica e prática da jurisdição constitucional no Brasil. 3. ed. Belo Horizonte: Fórum, 2014.

BRASIL. Constituição da República Federativa do Brasil de 1988. Diário Oficial da União, Brasília, $\quad 5 \quad$ out. $1988 . \quad$ Disponível em: http://www.planalto.gov.br/ccivil_03/Constituicao/Constituicao.htm. Acesso em: 06 out. 2018.

CAMPILONGO, Celso Fernandes. Assessoria jurídica popular: falsa promessa? In: SCHWARTZ, Germano. Organizador. Juridicização das esferas sociais e fragmentação do Direito na sociedade contemporânea. Porto Alegre: Livraria do Advogado, 2012. Cap. 12, p. 229-238. 
CANOTILlO, José Joaquim Gomes. O direito dos pobres no activismo judiciário. In: CANOTILlO, José Joaquim Gomes [et al.] Coord. Direitos fundamentais sociais. São Paulo: Saraiva, 2010. Cap. 2, p. 33-35.

DUARTE, Fransico Carlos; CADEMARTORI, Luiz Henrique Urquhart; BAGGENSTOSS, Grazielly Alessandra. Coerência do sistema jurídico em Luhmann com vistas ao fortalecimento do Direito do Meio Ambiente: uma proposta ao fechamento operacional e à abertura cognitiva da decisão judicial. In: ROCHA, Leonel Severo; DUARTE, Francisco Carlos (Coord.). Direito ambiental e autopoiese. Curitiba: Juruá, 2012. Cap. 9, p. 239-275.

FORNASIER, Mateus de Oliveira; ROGERIO, Marcele Scapin. Política, energia e impactos ambientais: da construção de hidrelétricas no Rio Uruguai sob a ótica da teoria dos sistemas autopoiéticos. Revista de Estudos Jurídicos UNESP, Franca, v. 22, n. 35, p. 165-203, jan./jun. 2018. Disponível em: https://ojs.franca.unesp.br/index.php/estudosjuridicosunesp/issue/archive. Acesso em: 17 abr. 2019.

GIORGI, Rafaelle de. Sobre o Direito Kafka, Dürrematt e a ideia de Luhmann sobre o Camelo. Revista Veredas do Direito, Belo Horizonte, v. 4, n. 7, p. 29-43, jan./jun. 2007. Disponível em: http://www.domhelder.edu.br/revista/index.php/veredas/article/view/56/42. Acesso em: 12 set. 2019.

GOMES, Magno Federici; FERREIRA, Leandro José. A dimensão jurídico-política da sustentabilidade e o direito fundamental à razoável duração do procedimento. Revista do Direito, Santa Cruz do Sul, $\mathrm{n}^{\circ}$ 52, v. 2, p. 93-111, maio/ago. 2017. Disponível em: http://dx.doi.org/10.17058/rdunisc.v2i52.8864. Acesso em: 17 abr. 2019.

GOMES, Magno Federici; FERREIRA, Leandro José. Políticas públicas e os objetivos do desenvolvimento sustentável. Revista Direito e Desenvolvimento, João Pessoa, v. 9, n. 2, p. 155178, ago./dez. 2018. Disponível em: https://doi.org/10.25246/direitoedesenvolvimento.v9i2.667. Acesso em: 18 jul. 2019.

KING, Michael; TORNHILL, Chris. Niklas Luhmann's theory of politics and law. London: Palgrave Macmillan, 2003.

LUHMANN, Niklas. O direito da sociedade. São Paulo: Martins Fontes, 2016a.

LUHMANN, Niklas. Sistemas sociais: esboço de uma teoria geral. Petrópolis: Vozes, 2016 b.

LUHMANN, Niklas. Sociologia do direito II. Rio de Janeiro: Edições Tempo Brasileiro, 1985.

NEVES, Marcelo. Aumento de complexidade nas condições de insuficiente diferenciação funcional: o paradoxo do desenvolvimento social na América Latina. In: SCHWARTZ, Germano (Org.). Juridicização das esferas sociais e fragmentação do Direito na sociedade contemporânea. Porto Alegre: Livraria do Advogado, 2012. Cap. 10, p. 199-207.

NEVES, Marcelo. Luhmann, Habermas e o Estado de direito. Lua nova, v. 37, n. 96, p. 93-105, 1996. Disponível em: http://www.scielo.br/scielo.php?script=sci_abstract\&pid=S010264451996000100006\&lng=en\&nrm=iso\&tlng=pt. Acesso em 23 ago. 2019. 
POGREBINSCHI, Thamy. Judicialização ou representação?: política, direito e democracia no Brasil. Rio de Janeiro: Elsevier, 2012.

ROACH, Kent. The myths of judicial activism. Supreme Court Law Review (2nd). v. 14, p. 297 330, 2001. Disponível em: https://papers.ssrn.com/sol3/papers.cfm?abstract_id=1144766. Acesso em: 14 maio 2019.

ROCHA, Leonel Severo; DUARTE, Francisco Carlos. Introdução. In: ROCHA, Leonel Severo; DUARTE, Francisco Carlos (Coord.). Direito ambiental e autopoiese. Curitiba: Juruá, 2012. p. 13-24.

SCHWARTZ, Germano; SANTOS NETO, Arnaldo Basto. O direito necessita da justiça?: reflexões sobre o tema em Kelsen e Luhmann. Revista Veredas do Direito, Belo Horizonte, v. 6, n. 11, p. 31-44, jan./jun. 2009. Disponível em: http://www.domhelder.edu.br/revista/index.php/veredas/article/view/4. Acesso em: 12 set. 2019.

SOUZA, Isabella Saldanha de; GOMES, Magno Federici. Ativismo judicial, democracia e sustentabilidade. Rio de Janeiro: Lumen Juris, 2015.

SUNSTEIN, Cass R. A Constituição parcial. Trad. Manassés Teixeira Martins e Rafael Triginelli. Belo Horizonte: Del Rey, 2008. 